\title{
Framework for apprenticeship in ethical comportment and formation
}

\author{
Kristen D Priddy * \\ College of Nursing and Health Innovation, University of Texas at Arlington, United States
}

Received: March 12, 2018

Accepted: July 19, 2018

Online Published: August 6, 2018

DOI: $10.5430 /$ jnep.v8n12p49

URL: https://doi.org/10.5430/jnep.v8n12p49

\begin{abstract}
Recently the literature on preparing students for nursing and other professions has emphasized the need for attention to civility, ethical comportment, and formation of professional identity. Nursing educators play a key role in supporting the formation of ethical comportment and professional nursing identity. Although a number of frameworks exist for the formation of identity, there are none that address the interaction between nursing educators and students or the role of nursing educators in implementing effective pedagogies for formation. In this article a framework developed from existing literature is proposed to guide nursing educator practice in stimulating and supporting the process of professional identity formation and ethical comportment in nursing students. The framework will also serve as a guide for future research in the process of formation of ethical comportment and professional identity.
\end{abstract}

Key Words: Formation, Professional identity, Nursing education, Nursing students, Ethical comportment, Reflection, Narrative, Modeling

\section{INTRODUCTION}

Ethical behavior in nurses is an essential element in providing safe, high quality health care. ${ }^{[1]}$ This requires the development of nursing students into professionals who possess the virtues to act as effective moral agents in the complex and sometimes difficult world of nursing practice, individuals who have formed a professional nursing identity and taken on the behaviors that express that identity. ${ }^{[2]}$

Nursing educators exert a significant influence on the formation of professional identity in students and model the comportment that expresses that identity. ${ }^{[3]}$ A number of authors argue, however, that development of professional ethics and formation of professional identity has been assumed rather than deliberately attended to by educators in the professions in general ${ }^{[4]}$ and in nursing in particular. ${ }^{[1,5-7]}$ Nursing edu- cators need to understand how professional nursing identity forms and skillfully apply pedagogies that support formation of identity and help students learn the comportment that expresses that identity. Professional identity formation is not completed at graduation but evidence suggests it begins during pre-licensure education. ${ }^{[1,5]}$ Without a clear understanding of how to influence the formation of professional nurses, nursing educators cannot identify or measure effective strategies, nor can they transfer this understanding to future nursing faculty. A literature review revealed a dearth of studies on formation of professional identity and ethical comportment in nursing students, supporting the need to begin developing a coherent model that nursing educators can use to support students' growth and development into fully formed, ethical professional nurses.

\footnotetext{
${ }^{*}$ Correspondence: Kristen D Priddy; Email: priddy@uta.edu; Address: College of Nursing and Health Innovation, University of Texas at Arlington, United States. 
The Framework for Apprenticeship in Ethical Comportment and Formation (FAECF, see Figure 1) was developed in response to the need to understand the process of formation of professional nursing identity and ethical comportment The purpose of the FAECF is to help nursing educators understand the process of formation and apply effective instructional strategies. This paper includes a discussion of the theories and research from which the framework was developed. The concepts within the framework and the relationships among the concepts are described. Finally, the educational and research applications of the framework are discussed.

\section{Background}

In the landmark study, Educating Nurses: A Call for Radical Transformation, Benner and colleagues ${ }^{[1]}$ describe the framework of professional education as three "high-end apprenticeships". A high-end apprenticeship entails experiential learning, reflection, and guidance by experienced mentors. Formation of professional identity requires integration of apprenticeships in (a) knowledge, (b) skilled know-how, and (c) ethical comportment and formation. ${ }^{[1]}$ Carnegie scholars Colby and Sullivan ${ }^{[4]}$ emphasized that these three professional apprenticeships cannot be carried out separately. However, Benner et al. ${ }^{[1]}$ found that nursing students experience the three apprenticeships separately from each other, leading to difficulties integrating knowledge presented in the classroom with the skilled know-how and ethical comportment expected in clinical settings. In response to these findings, Benner et al. ${ }^{[1]}$ called for an integration of the three professional apprenticeships in nursing education. This integration requires profound change from the mode of teaching facts in the classroom, skills in the laboratory, and practice in clinical setting. ${ }^{[1]}$ This paper focuses on the apprenticeship in ethical comportment and formation, which Colby and Sullivan identified as the apprenticeship that brings all three together in the formation of professionals. The aim is to present a cohesive framework that can guide nursing educators in integrating the apprenticeship in ethical comportment and formation in all undergraduate nursing education settings, classroom, laboratory, and clinical.

Several frameworks exist for the development of professional nursing identity, ${ }^{[8,9]}$ formation of an ethical nursing identity, ${ }^{[6]}$ and development of nursing clinical judgment. ${ }^{[10]} \mathrm{Re}-$ search to develop these models has focused on the student or developing nurse. However, formation is an interactive process. As noted by Benner et al. ${ }^{[1]}$ formation occurs in a milieu of "skilled practice and highly relational work" (p. 86). Transforming from a layperson to a professional nurse is a process of ascribing new meanings to new experiences, and this process occurs through interaction with patients, colleagues, other members of the health care team, and nursing faculty. ${ }^{[1-13]}$ Theories about the development of nursing students can be used to guide education practice more effectively when the role of the educator is described. None of the existing theories address the interaction between nursing educators and students. Therefore there is a need for a cohesive theory that can be used to guide the practice of the nursing educator in supporting development of ethical comportment and formation of professional identity.

\section{MeTHODS}

One aim of theory synthesis, according to Walker and Avant, ${ }^{[14]}$ is to bring together related information that is separate in the literature "into a more theoretically organized form" (p. 143). As noted above, existing theories have focused on the student without integrating the role the educator plays in creating an environment and using pedagogies that support formation of professional identity and the ethical comportment that expresses that identity. Using Walker and Avant' ${ }^{[14]}$ theory synthesis process, I drew on theoretical and research literature, personal experiences from my early years as a nurse, and experiences as a nursing educator to develop a model of apprenticeship in ethical comportment and formation. First, I identified and described the characteristics of focal concepts such as "ethical comportment" and "student as moral agent" and specific pedagogies for formation such as "narrative". Relationships among these concepts emerged from research and theoretical literature on education of professionals in general and of nurses in particular as ethical and expert practitioners. Further review of the literature clarified the relationships between the concepts. Based on the literature review, the role of content such as "ethical theories and codes", and of pedagogies such as "experiential learning" and "reflection" were added. After seeking feedback from fellow doctoral students and faculty, I altered some terms for clarity. Relationships were further clarified in the process of working with artists to develop the model depicted in the figure below. The resulting FAECF model represents the entry of a novice student into the community of nursing practice and his or her movement over time toward formation of professional identity through application of appropriate pedagogies by the nursing educator (see Figure 1).

\section{LITERATURE REVIEW}

This paper was largely inspired and informed by the Carnegie Foundation for the Advancement of Teaching studies on Preparation for the Professions in the United States, ${ }^{[1,4]}$ as well as the work of Dreyfus, Dreyfus, and Benner on acquisition of expertise in nursing practice. ${ }^{[5,15-17]}$ Additional searches were conducted in the Cumulative Index of Nurs- 
ing and Allied Health Literature (CINAHL) and Education Information Resources Center (ERIC) databases and Google Scholar using search terms "ethical comportment", "professional identity", "ethics and nursing education" and "formation of identity and nursing education". Additional sources were identified in the reference lists of articles, theses, and books included in the literature review.

\subsection{Formation of professional identity and ethical com- portment}

Using the methodology of previous studies in the Carnegie Preparation for the Professions series, Benner et al. ${ }^{[1]}$ conducted a mixed methods study of nursing education in the U.S. The first phase of data collection included classroom and clinical observations and focus group interviews of 586 students, faculty, and administrators at 9 schools of nursing known to exemplify excellence in teaching. Subsequently, the researchers developed on-line surveys to confirm the findings of their qualitative analysis. Surveys were completed by members of the American Association of Colleges of Nursing $(n=123)$, the National League for Nursing $(n=8,468)$ and National Student Nurses Association $(n=1,648)$. The researchers found that formation of professional identity and ethical comportment are strengths of U.S. nursing programs, using pedagogies such as situated coaching, modeling, and experiential learning in the clinical arena. However, although very effective in clinical settings, nursing programs in general do not effectively teach professional identity and ethical comportment in the classroom. In proposing the FAECF I seek to create a cohesive framework that can be applied in the classroom as well as the clinical area.

Crigger and Godfrey ${ }^{[6]}$ proposed a framework for nurse professionals (FrNP) that begins with the nurse or student as moral agent deliberating and acting on choices and either moving toward (flourishing) or away from (slips) the telos (ideal in nursing practice). Their purpose in developing the model, in part, was to integrate the ethical theories of deontology, teleology, and virtue ethics in nursing practice. Formation is a process of practicing, making mistakes, and improving, so Crigger and Godfrey provide a simple visual representation of the process as stairsteps with students moving upward toward the ideal or making slips downward, reflecting on the slips, and returning to upward movement.

Tanner $^{[10]}$ developed a model that illustrates four aspects of clinical judgment: noticing, interpreting, responding, and reflecting. The model depicts the socially embedded and cyclical nature of experience, reflection, and action. Although this model reflects the reasoning of experienced nurses, nursing faculty have used it to guide novices in debriefing simulation experiences.

Published by Sciedu Press
The model I propose integrates the findings of Benner et al., ${ }^{[1]}$ elements of the FrNP and Tanner's clinical judgment model and expands on them by providing more detail on applicable pedagogies and by identifying specific points for faculty guidance or intervention.

\subsection{Formal ethics and values codes}

Although nursing educators often believe they are teaching students the values of nursing, there is little evidence that students change their values over the course of their nursing education. ${ }^{[8,9]}$ Students tend to choose nursing because they already possess the values of professional nursing. In Enns ${ }^{[9]}$ grounded theory study on the formation of professional nursing identity, the initial choosing nursing phase involved students aligning their personal values, preferences, and attributes with an emerging understanding of the realities of nursing. Personal values that influence choosing the nursing major were frequently "caring" and the ability to "make a difference". [9] Students described formal ethics codes as "essentially common sense" values that they already possessed. ${ }^{[9]}$ Learning about these codes helped students align their existing values with the nursing profession and gave them a tool for reflection but did not fundamentally change their values. Advocacy was a new value to many nursing students, as was understanding the complexity of knowledge and high level of responsibility nurses hold. Students learned a great deal from modeling and used their existing values to judge good nurses and bad nurses. ${ }^{[8,9]}$

\subsection{Role models}

Role models are major influencing factors on formation in nursing students, with nursing educators being the strongest role models, followed by clinical preceptors and family or friends. ${ }^{[18]}$ Students learn about ethical comportment from bad examples as well as from good examples of nursing behavior. ${ }^{[1]}$ It is important to note that the first nurse a student spends significant time with may very well be the nurse standing at the front of the classroom, and nursing instructors can be either good or bad examples. Students describe instructors as either supportive and encouraging or unwilling to empathize with students. ${ }^{[9]}$ Students note that when they make patient care errors they need instructors to be supportive rather than punitive. ${ }^{[9]}$

Nursing instructors model nursing behavior both in the clinical setting and in the classroom. Embodied caring in the classroom is critical in the formation of caring attitudes and caring comportment in students. ${ }^{[8,19]}$ Enns $^{[9]}$ concluded that instructors conveyed caring through showing interest in students, creating a safe learning environment of trust and respect, taking time to explore and meet student needs, sharing 
their own experiences, and being flexible. Students also described non-caring behaviors they observed in nursing instructors and peers. Non-caring behaviors in the classroom included tone of voice, talking over others or having side conversations, lack of preparation for class, and instructor inflexibility. Shaha et al. ${ }^{[20]}$ used a community-based participatory research design to ascertain student perceptions of teaching excellence from a convenience sample of 41 baccalaureate, master's, and doctoral nursing students at one leading private nursing school in the U.S. Seven focus groups were interviewed by a researcher with minimal teaching involvement, data were analyzed using constant comparative analysis, and credibility of results was strengthened using member checking. Analysis of focus-group transcripts revealed that students want teachers to be well-prepared as educators, demonstrate creativity and courage, foster a collaborative environment in the classroom, treat students with respect, adapt to student needs, and recognize that nursing is a new language for undergraduate students. Faculty model caring comportment by attending to these student needs.

\subsection{Problem-based learning}

Only two studies were found that investigated the influence of a specific classroom instructional strategy on formation of professional identity. Problem-based learning (PBL) is a constructivist approach to learning in which students work in small groups to solve problems. Instructors act as facilitators rather than lecturers and offer feedback on group work. ${ }^{[19]}$ Oosterbroek conducted a focused ethnography on preparing students to care in a PBL classroom in Canada. Triangulation of data was achieved through participant observation of 77 fourth year students in PBL tutorial groups, interviews with 10 student participants, and a focus-group interview with 6 instructors. Appropriate procedures to insure rigor were used, including attention to reflexivity, credibility, dependability, confirmability, and transferability. Oosterbroek found that PBL helped develop a caring environment of trust and respect. Instructors could give attention to small groups of students and students could bond with one another. PBL students also learned about the importance of self-care.

Williams et al. ${ }^{[21]}$ also conducted a focused ethnography to find out what characteristics graduates of a Canadian university nursing program developed in a problem/contextbased learning (CBL) environment. The researcher initially intended to interview graduates with two to five years of experience. However, this approach did not generate an adequate sample, so all graduates of the nursing program were recruited. Eight focus groups and 23 individual interviews were conducted. Data were analyzed by a team of researchers using constant comparative analysis. Interviews were conducted until saturation was reached. Graduates with a range of experience believed that CBL helped them adopt essential skills and values, described in three main themes: "self-aware and self-directed critical thinkers, patient advocates engaged in evidence-based holistic practice, and interdisciplinary team members able to handle conflict". [21] Among the values and skills identified were: life-long learning, ability to give and receive feedback, conflict-resolution, self-awareness of biases, advocacy, supporting patient autonomy, change agency, teamwork, leadership, respect, and awareness that their behavior represents the nursing profession.

\subsection{Narrative}

Many authors describe the importance of narrative, the telling of one's stories, in formation. Benner et al. ${ }^{[1]}$ noted that narrative pedagogies were among the most effective observed in their study and recommended that faculty develop pedagogies that involve stories from nurses and patients and provide opportunities for students to journal or tell their own stories. Students experienced caring when instructors shared personal stories. ${ }^{[19]}$ Benner et al. ${ }^{[5]}$ described the importance of narratives in developing ethical expertise and sharing that expertise among different nursing communities. In other words, students can learn a great deal about ethical comportment by hearing the stories of expert nurses.

\subsection{Reflection}

Reflection in and on practice is described more frequently than any other pedagogy in the literature. As Lewin ${ }^{[22]}$ points out, reflection is the process in which one makes moral choices about which attitudes and behaviors to integrate into one's identity. The use of structured reflection goes back to the philosophies of Dewey on constructing new knowledge and making choices about future actions through reflecting on perplexing experiences. ${ }^{[1,23]}$ Kolb's work on experiential learning includes reflection as a necessary stage following experiences to help the learner make meaning of new experiences. ${ }^{[23]}$ The classic work of Schön describes reflecting during (reflection-in-action) and after (reflectionon-action) experiences for the purpose of learning how to interpret knowledge and apply it in varying contexts, ${ }^{[23]}$ and Mezirow's Theory of transformative learning describes levels of skill in reflection that are necessary to transform the thinker. ${ }^{[12,23]}$ Benner et al. ${ }^{[1]}$ identify deliberate use of a cycle of practice and reflection in the clinical area as one of the great strengths of nursing education, noting that the effectiveness of this pedagogy is a strong argument for applying it in the classroom as well. Reflection can be written in response to prompts that guide the student to think deeply. Reflection can also be verbal or dialogical between individuals or in 
groups, leading Benner et al. ${ }^{[1]}$ to recommend continuation of the practice of clinical post-conferences. Both written and dialogical reflection require that nursing educators become adept at posing questions skillfully.

\subsection{The student as moral agent}

One of the roles of nursing faculty is to skillfully facilitate the movement of the student from novice to advanced beginner and to lay the foundation of nursing values that support the later development of expertise. Tanner ${ }^{[10]}$ advocates helping students develop as moral agents as part of helping them learn to "think like a nurse" (p. 210). Crigger and Godfrey ${ }^{[6]}$ agree with the current concerns that development of individual healthcare professionals as moral agents has been overlooked in curricula. They ${ }^{[6]}$ describe the nurse lacking a firm grounding in moral character and professional identity as "an empty uniform with no one inside" (p. 4) who simply carries out nursing tasks.

Students begin their nursing education as novices, but they do not arrive as blank slates. Students enter nursing education as agents, bringing with them a unique set of experiences, values, and expectations. ${ }^{[6,15]}$ Benner and colleagues ${ }^{[5]}$ note that nurses at each stage of the five-stage model of skill acquisition have a unique form of agency. Students are novices; graduates enter practice at the advanced beginner level with a form of agency that is dependent on rules, schedules, and orders. When the needs of the situation exceed the advanced beginners' experience, they delegate up to the expertise of more experienced colleagues. At the competent level, nurses have attained a level of agency that is less dependent on the expertise of others. ${ }^{[5]}$ Notably, progression beyond the competent level to proficiency and expertise depends on formation of a professional identity as a moral agent. Nurses who do not view their work as significant and themselves as making a difference do not become expert nurses. ${ }^{[5,24]}$ Therefore the role nursing educators play in supporting formation of professional identity and ethical comportment is critical in the future development of expert nurses.

\section{FRAMEWORK}

Based on the literature reviewed, the Framework for Apprenticeship in Ethical Comportment and Formation (FAECF) was constructed and is described below (see Figure 1). Students move from a layperson's understanding of what a nurse is and does to the realities of practice. They develop an understanding of the central values of nursing and adopt the virtues necessary to carry out the ethos of the nursing profession. ${ }^{[6]}$ Formation continues after students leave the educational setting and begin employment in a practice setting.

The upper and lower boundary lines of the framework indi- cate the community of practice within which the process of formation occurs. ${ }^{[5]}$ Formation of professional identity and ethical comportment is depicted as an ongoing process over time. The student beginning to form a professional identity is depicted as an unformed shape; nurses with a fully formed professional identity are depicted as fully formed circles. Pedagogies and points of intervention for nursing educators are noted in bold text. The FAECF model begins when the student enters the community of practice. Development of professional identity continues beyond nursing school and through the first few years of nursing practice, indicated by the open-ended, right side of the FAECF diagram, and the ongoing practice-reflection cycle of the professional nurse.

\subsection{Formation, professional identity, and ethical com- portment}

Before exploring how nursing educators can effect formation and ethical comportment in nursing students, it is important to understand what these terms mean and the relationship between them. Benner and colleagues ${ }^{[1]}$ describe formation as "those changes in identity and self-understanding that occur in moving from being a lay person to a professional... literally transforming [students'] ways of perceiving and acting in situations" (p. 86). Godfrey and Crigger ${ }^{[2]}$ offer a succinct and practical definition of professional nursing identity that is the result of this formation: “...professional identity in nursing is defined as a sense of oneself that is influenced by characteristics, norms, and values of the nursing discipline, resulting in an individual thinking, acting, and feeling like a nurse." Embedded in these definitions is the notion that formation of identity entails seeing oneself and the world in new ways, aligning one's values with the telos or notions of the good of the profession, and then engaging in behaviors (comportment) that express that identity. Behaviors that express a professional identity are sometimes identified in the broad term "professionalism". ${ }^{[1]}$ The term professionalism often includes very concrete behaviors with little contextual variation, such as being on time or complying with a dress code, or vague expectations related to demeanor and communication styles. The term "ethical comportment" is used here to specifically describe those behaviors that express professional identity and may vary with the patient context. These new value-laden behaviors (ethical comportment) may feel quite awkward at first, but over time become a natural outflow of one's professional identity.

\subsection{Student}

The student is depicted as an unformed shape that progressively takes the form of a defined circle as the student develops a professional nursing identity. The point at which a student enters the community of practice varies with the stu- 
dent and the curriculum. In some programs, this entry occurs I suggest that students enter the community of practice at in the first semester of the freshman year. In other programs, students do not begin taking nursing courses until their first clinical course after all pre-requisites have been completed. the point when nursing educators first expose them to the discipline of nursing and begin to guide students' thinking experiences.

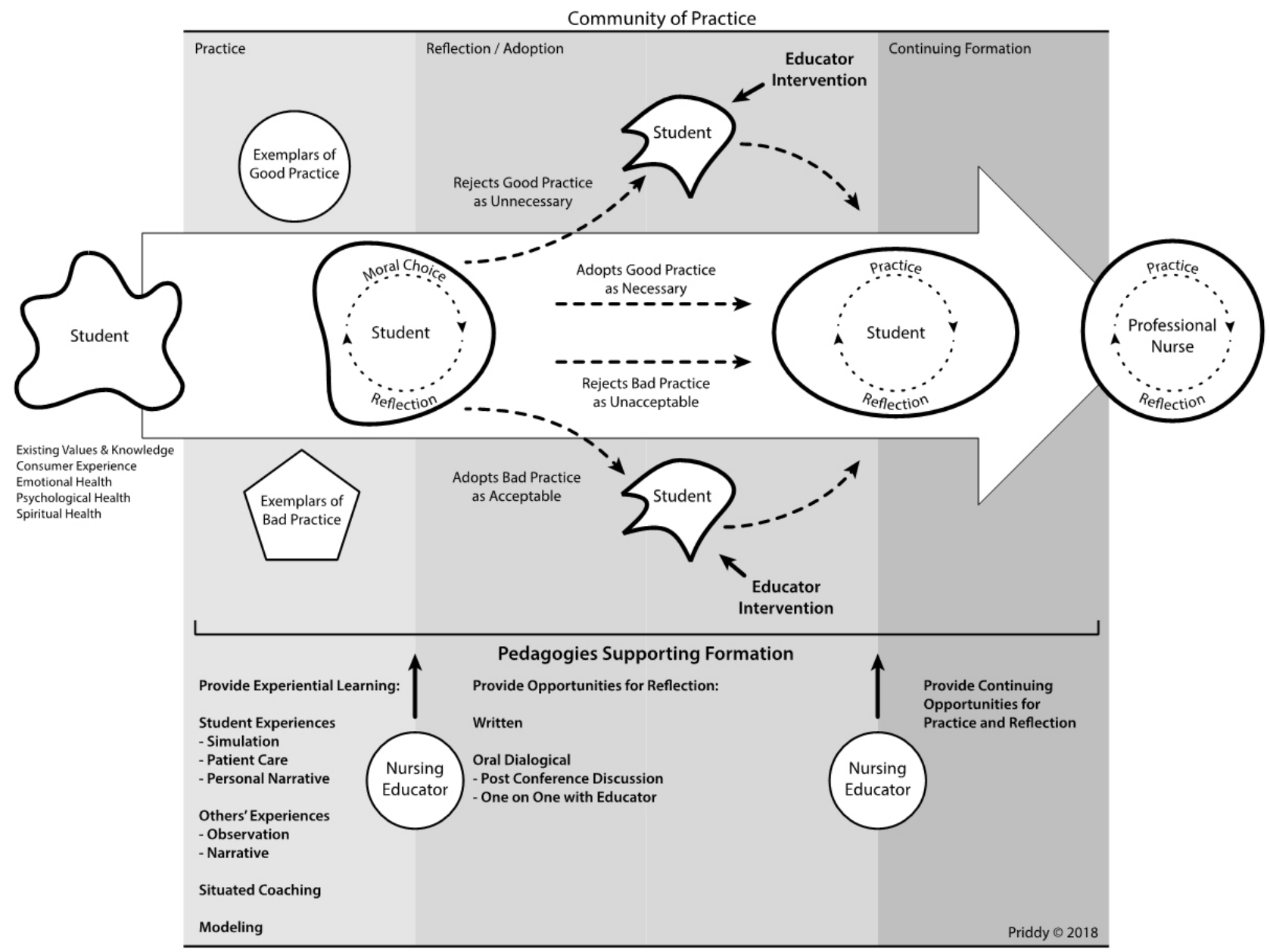

Figure 1. Framework for Apprenticeship in Ethical Comportment and Formation (FAECF)

Each student enters nursing education with a unique combination of experiences, values, and knowledge, including some measure of experience as a consumer of health care. ${ }^{[6,15]}$ Research evidence suggests that students choose to pursue nursing because they perceive the nursing profession as congruent with their personal values. ${ }^{[8,9]}$ Students vary in age from recent high-school graduates to older adults beginning a second or third career. Some students have worked closely with nurses in their employment settings, others have grown up with nurses in their families, and others have limited direct exposure to the behavior and attitudes of nurses. In addition to varying levels of experience with the nursing community of practice, each student has a level of emotional, psychological, and spiritual health that will impact his or her ability to engage with, interpret, and integrate clinical experiences into a definition of self as a professional.

\subsection{Nursing educator practice}

An assumption in the FAECF model is that nursing educators have well-formed professional nursing identities. Therefore, circles depict nursing educators. The role of the nursing educator is to create the learning environment and implement pedagogies that support formation of nursing identity and learning ethical comportment. The literature supports several pedagogies that impact this process. These include experiential learning, the use of narrative, situated coaching, and modeling. Actively supporting the practice-reflection cycle is an essential task in supporting the formation of professional identity. Although teaching ethical theories, principles, and codes does not do much to change students' values, introducing this language is important in helping students express 
and explore those values. Occasionally educators must also intervene to correct students who are adopting attitudes and practices outside the ethos of nursing.

\subsubsection{Experiential learning, narrative, and situated coach- ing}

The embodied knowing of everyday ethical comportment is embedded in nursing practice and is therefore formed through experiential learning. ${ }^{[1,15,17]}$ Experiences may be the student's own, or the experiences of others through observation and narrative. Experiential learning can occur through experiences of direct patient care, in simulations of patient care, or problem-based learning in the classroom. Narrative, the telling of one's own story or hearing the stories of others, is particularly important in the process of forming a new identity. ${ }^{[5,19,22]}$ Experiential learning can occur imaginatively through narrative and reflection on those stories. While the student is engaged in experiential learning, nursing educators interact with students through situated coaching. Situated coaching means giving verbal guidance and modeling nursing behaviors and attitudes within the context of a specific care situation. Like experiential learning, situated coaching can occur in hands-on clinical situations, in laboratory settings, and imaginatively in the classroom when the nursing educator thinks aloud about a patient situation.

\subsubsection{The practice-reflection cycle}

An essential role of the nursing educator is providing structured opportunities for practice and reflection on that practice. The cycle of practice and reflection is indicated by the dotted circular arrows within the forming professional nurse. Experience is only the first, external step in formation. In these experiences, students are exposed to exemplars of both good and bad practice, and they must decide which attitudes and behaviors to adopt, and inherently ethical choice. Reflection is an essential step in the decision to accept or reject values and behaviors into one's professional identity. Practice is continued experiential learning in which the student applies the behaviors and attitudes resulting from reflection.

The FAECF model identifies two pathways. Students are inevitably exposed to exemplars of good nursing practice, depicted as a circle, and to exemplars of bad practice, depicted as a polygon with sharp corners. The student reflects on these experiences and judges and adopts exemplars of good practice as necessary or unnecessary for future practice, and exemplars of bad practice as acceptable or unacceptable in future nursing practice. The center path is toward formation as a professional who pursues the good in nursing and who is equipped to continue developing as professional nurse. When a student reflects on exemplars that are consistent with the ethos of nursing and adopts them as necessary for his or her own practice or reflects on exemplars that oppose the ethos of nursing and rejects them as unacceptable behaviors and attitudes, the student begins to form himself or herself as a professional nurse. For example, when a student observes effective, respectful communication, considers the impact of this mode of communication on patient outcomes, and emulates the behavior, the student is engaging in formation as a professional nurse.

Students may also make ethical choices that put them on a trajectory toward formation outside the ethos of nursing, depicted by an undefined shape with round and sharp edges. When a student judges exemplars of good practice as unnecessary for his or her own professional practice, the trajectory of formation is no longer directed toward professional nursing identity. Likewise, when a student experiences exemplars of bad practice and adopts them as acceptable attitudes and behaviors, he or she moves toward formation outside the ethos of nursing. For example, if a student hears nursing staff belittling a colleague who consistently practices a safety protocol, the student may adopt the attitude that the safety protocol is unnecessary for practice. The student would then deem shortcuts that put a patient at risk as acceptable and begin practicing those shortcuts.

The nature of practice varies with the student's progression through the education program and with the setting. What is practiced in the first-year in a simulation laboratory is different than practice in the final year in a critical care unit. Practice is not limited to direct patient care settings and skills laboratories. Practice can be designed into classroom instruction by including narrative and simulation experiences such as problem-based case scenarios.

Formation continues through a cycle of practice, reflection, and adoption. Research indicates that novice nurses need to spend a greater proportion of their time on reflection than experienced nurses. ${ }^{[5,15,16]}$ Over time, everyday ethical comportment requires less and less reflection. It is behavior that flows out of a nurse's fully formed professional identity. The expert nurse engages fully in practice and uses focused reflection and deliberation only in unusual cases.

\subsubsection{Educator intervention}

Nursing educators need to actively intervene when students begin to veer away from formation within the ethos of nursing. Intervention may occur through verbal correction and redirection, clinical evaluations, or through formal disciplinary procedures. Faculty can use narratives of their own mistakes to model how professionals handle ethical slips. ${ }^{[1,6]}$ Incidents of scholastic dishonesty require timely and clear responses from faculty. In addition to following formal institutional procedures in these cases, faculty can help students 
see scholastic dishonesty through the lens of professional character and conduct. Requiring students to engage in structured reflection is particularly important when ethical slips occur. Timely intervention may restore the trajectory of a students' formation toward a professional nursing identity.

\section{Practice AND ResearCh IMPlications}

The role of educators is to intentionally design instruction that guides students toward the knowledge, skilled knowhow, and ethical comportment necessary for excellent nursing practice. ${ }^{[1]}$ Instructional design should explicitly include classroom and clinical pedagogies to support the formation of professional identity and the development of everyday ethical comportment in students. Pedagogies may include providing opportunities for experiential learning, situated coaching, sharing narratives, and reflection activities, as well as didactic instruction.

Nursing educators should construct opportunities for experiential learning as early in the curriculum as possible. Instructors can use a variety of methods to help students develop clinical imagination so that experiential learning can begin in the classroom. ${ }^{[1]}$ Even in pre-nursing courses that are limited to the classroom, nursing educators can help students cast their minds into the patient context through practitioner and patient narratives, unfolding case studies, and simulation. During simulated and real patient care experiences, nursing educators engage in situated coaching, guiding students' interpretations and actions in real time. Educators also need to value and encourage the use of narratives by sharing their own stories, asking for narratives from preceptors and patients, and providing time for students to share narratives of experiences in class or during post-conference discussions. ${ }^{[1,5,19]}$ The impact of modeling cannot be underestimated. Educators should be intentional about the behaviors and attitudes they are modeling and make deliberate use of both good and bad modeling students are exposed to. ${ }^{[25]}$

Formation is ultimately self-formation, occurring through reflection and adoption of attitudes and behaviors. ${ }^{[22]}$ Recognizing the importance of reflection, nursing educators can deliberately assign written reflection assignments and provide time for oral reflection and dialogue between students. Nursing educators should also model reflective practice by engaging in personal reflection, reflecting aloud for students, and engaging in civil discourse about practice with other members of the health care team. Educators in the nursing discipline may also need to further develop skills in formulating questions and exercises for reflection.

Reactive faculty intervention may also include coaching or corrective actions taken when students exhibit uncaring or uncivil behaviors or make errors in clinical care. Disciplinary interventions are necessary when students engage in scholastic dishonesty or unethical practices in the clinical setting. Effectively carrying out these interventions requires the skills and courage to recognize and confront uncivil or dishonest behavior. Educators must also develop responses that help students return to a trajectory toward formation of professional identity.

Ethical theories, principles, laws, and codes have an important place in nursing education, but have limited effectiveness in formation of professional identity. ${ }^{[1,7-9]}$ Theories, principles, and codes are a shared language of ethics necessary for intra- and interdisciplinary collaboration. They can and should be introduced early in the curriculum and revisited throughout as students strive to interpret their experiences. However, when taught in a decontextualized fashion these ethical abstractions do little to support ethical formation. ${ }^{[1,7]}$ In the classroom, nursing educators can use simulations, unfolding case studies, and narratives to help students explore their own values and give students practice in applying ethical thinking. Educators can model how experienced nurses integrate ethical language and contextual factors into their thinking, decision-making, and behavior. Educators can also construct dialogical and values exploration exercises across the curriculum.

Examination of the FAECF raises a number of research questions. The limitation of this model is that it was developed through a process of integrating published research literature and personal experiences rather than being grounded in current practice. A grounded theory approach would further illuminate the process of formation of professional identity and could address a number of questions: How do nursing educators and students perceive the process of formation of professional identity and ethical comportment? What is the usual progression at each stage of nursing education? What are nursing educators doing to bring about this formation, formally and informally?

Future research could address important related questions: Which pedagogies are effective in bringing about formation? Do pedagogies vary in effectiveness based on student characteristics? Can effective pedagogies be applied across health care disciplines, or to interprofessional education? And finally, how can formation be evaluated? Answering these questions will require rigorous qualitative and quantitative research.

The FAECF could be used to explore differences in pedagogical approaches to formation based on institutional characteristics (public or private; faith-based or secular; large or small). The effects of different student characteristics 
(gender, age, previous careers) could also be explored. The FAECF might also provide a framework for exploring the expanding professional identity of registered nurses with Associate's degrees who are enrolled in baccalaureate completion programs. Finally, an important question is whether students and nurses with established identities and behaviors outside the ethos of nursing can be re-formed into nurses with an ethical professional identity. The FAECF could be used to identify ways to help these individuals complete their development as ethical professional nurses.

\section{Conclusion}

The purpose of the FAECF is to identify points where nursing educators can influence formation of professional identity and ethical comportment. Using Walker and Avant's ${ }^{[14]}$ the- ory synthesis method, the FAECF was developed with the aim of providing a cohesive framework that could be applied in the classroom, laboratory, or clinical setting across pre-licensure nursing curricula. The model as currently derived can be used to guide nursing educators in deliberate efforts to support formation of professional identity and ethical comportment. The model may also be used to research the effectiveness of various pedagogies for formation and ethical comportment. Future applications may include professional education of nurses taking on new roles as advanced practice nurses, in disciplines outside nursing, and perhaps even in interprofessional education efforts.

\section{CONFlicts of InTEREST Disclosure}

The author declares that there is no conflict of interest.

\section{REFERENCES}

[1] Benner P, Sutphen M, Leonard V, et al. Educating nurses: a call for radical transformation. San Francisco, (CA): Jossey-Bass; 2010. 304 p.

[2] Godfrey N, Crigger N. Professional identity. In: Giddens JF, editor. Concepts for nursing practice. 2nd ed. St. Louis (MO): Elsevier; 2017. 379-86 p.

[3] Johnson M, Cowin LS, Wilson I, et al. Professional identity and nursing: contemporary theoretical developments and future research challenges. Int Nurs Rev [Internet]. 2012 Dec [cited 2017 Mar 7]; 59(4): 562-9.

[4] Colby A, Sullivan WM. Formation of professionalism and purpose: Perspectives from the preparation for the professions program. Univ St Thomas Law J [Internet]. 2008 [cited 2017 Mar 7]; 5(2): 404-27.

[5] Benner PE, Tanner CA, Chesla CA. Expertise in nursing practice: caring, clinical judgment, and ethics. 2nd ed. New York: Springer Publishing Company; 2009. 497 p.

[6] Crigger N, Godfrey NS. The making of nurse professionals: a transformational, ethical approach. Sudbury (MA): Jones and Bartlett Learning; 2011. 145 p.

[7] Woods M. Nursing ethics education: are we really delivering the good(s)? Nurs Ethics [Internet]. 2005 [Cited 2018 Jun 7]; 12(1): 5-18.

[8] Duquette LM. Effects of nursing education on the formation of professional values [dissertation]. Toronto (ON, Canada): University of Toronto; 2004. $430 \mathrm{p}$.

[9] Enns B. Finding my own way: Nursing identity development from layperson to new $\mathrm{BN}$ graduate [dissertation]. [Athabasca, $\mathrm{AB}$, Canada)]: Athabasca University; 2014. 187 p.

[10] Tanner CA. Thinking like a nurse: A research-based model of clinical judgment in nursing. J Nurs Educ [Internet]. 2006 [cited 2017 Mar 7]; 45(6): 204-11.

[11] Corbin J, Strauss A. Basics of qualitative research. 3rd ed. Los Angeles (CA): Sage Publications; 2008.

[12] Kitchenham A. The evolution of John Mezirow's transformative learning theory. J Transformative Educ. 2008 [cited 2017 Mar 7]; 6(2): 104-23.

[13] Strauss A. The Chicago tradition's ongoing theory of action/interaction In: Creating sociological awareness: Collective images and symbolic representations. New Brunswick (NJ): Transaction Publishers; 1991. p. 3-32.

Published by Sciedu Press
[14] Walker LO, Avant KC. Strategies for theory construction in nursing. 5th ed. Upper Saddle River (NJ): Pearson, 2011. 243 p.

[15] Dreyfus HL, Dreyfus SE. relationship of theory and practice in the acquisition of skill. In: Benner PE, Tanner CA, Chesla CA, editors. Expertise in nursing practice: caring, clinical judgment, and ethics. 2nd ed. New York: Springer Publishing Company; 2009. p. 1-29.

[16] Dreyfus HL, Dreyfus SE. The ethical implications of the five-stage skill-acquisition model. Bull Sci Technol Soc. 2004 Jun [cited 2017 Mar 7]; 2(4): 251-64.

[17] Benner P. The roles of embodiment, emotion and lifeworld for rationality and agency in nursing practice. Nurs Philos. 2001 Jul [cited 2017 Mar 7]; 1(1): 5-19.

[18] Kelly B. The professional self-concepts of nursing undergraduates and their perceptions of influential forces. J Nurs Educ. 1992 [cited 2017 Mar 7]; 31(3): 121-5.

[19] Oosterbroek TA. Preparing to care: Creating a culture of caring in problem-based learning tutorial groups [master's thesis]. Lethbridge (AB, Canada): University of Lethbridge; 2009. $131 \mathrm{p}$.

[20] Shaha M, Berg J, Wenzel J, et al. Excellence in teaching and learning: Students' perspective. J Nurs Educ Pract. 2013; 3(12): 35-46.

[21] Williams B, Spiers J, Fisk A, et al. The influence of an undergraduate problem/context based learning program on evolving professional nursing graduate practice. Nurse Educ Today. 2012; 32(4): 417-21. PMid:21458115 https://doi.org/10.1016/j.nedt.2011.03 .002

[22] Lewin P. The stories of ethics: Ethical comportment and the stories we tell. Cybern Syst. 1999 May [cited 2017 Mar 7]; 30(4): 331-40.

[23] Horton-Deutsch S, Cara C. Learning through reflection and reflection on learning: pedagogies in action. In: Sherwood GD, Horton-Deutsch S, editors. Reflective practice: transforming education and improving outcomes. 2nd ed. Indianappolis (IN): Sigma Theta Tau International; 2017. $104-134 \mathrm{p}$.

[24] Rubin J. Impediments to the development of clinical knowledge and ethical judgment in critical care nursing. In: Benner P, Tanner C, Chesla C, editors. Expertise in nursing practice: caring, clinical judgment, and ethics. 2nd ed. New York: Springer Publishing Company; 2008. 171-98 p.

[25] Kenny NP, Mann KV, MacLeod H. Role modeling in physicians' professional formation: reconsidering an essential but untapped educational strategy. Acad Med. 2003; 78(12): 1203-10. 